\title{
fMRI study of self vs. others' attributions of traits consistent with evolutionary understanding of the self
}

\author{
Gonzalo Munevar' ${ }^{1}$, Matthew L. Cole ${ }^{2 *}$, Yongquan Ye ${ }^{3}$, Jie Yang ${ }^{3}$, Yi Zheng ${ }^{4}$, Uday Krishnamurthy ${ }^{3}$ and Mark Haacke ${ }^{3}$ \\ *Correspondence: mcole@ltu.edu

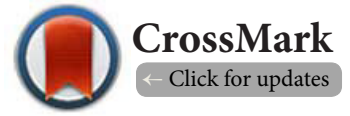 \\ 1Psychology Program, Lawrence Technological University, Southfield MI, USA. \\ ${ }^{2}$ Management and Marketing Program, Lawrence Technological University, Southfield MI, USA. \\ ${ }^{3}$ MR Research Facility, Wayne State University, Detroit, MI, USA. \\ ${ }^{4}$ Psychology Department, Stonybrook University, Stonybrook, NY, USA.
}

\begin{abstract}
Background: An evolutionary explanation concerning neural substrates of the self requires the ability by the brain to coordinate new sensory information in light of the organisms' internal states and in the context of its personal history and genetic inheritance. The aim of the present study was to demonstrate the experimental feasibility of a conception of the self as a distributed system consistent with predictions derived from evolutionary biology and neuroscience.

Methods: We used a 3T fMRI to compare Self vs. Other conditions in which 90 personality and 90 non-personality trait adjectives were rated as to whether they applied to Self, Best Friend, or Bill Gates, in a blocked-design paradigm.

Results: When comparing Self vs. Best Friend, we found significant activation in the dorsal posterior cingulate (BA 31), an area where the brain distinguishes egocentric and allocentric orientation, as well as in the substantia nigra and caudate nucleus, which are areas that reward successful action in the basal ganglia. We found an overlap of activation in the anterior cingulate cortex (BA 24) between the Self vs. Bill Gates and Best Friend vs. Bill Gates although the activation was greater in the former, as should be expected within an evolutionary approach.

Conclusions: The present study complements other neuroimaging studies of the self while resolving contradictions and paradoxes created by more traditional conceptions of the self.
\end{abstract}

Keywords: Self-attribution, fMRI, neuroimaging, evolutionary explanation, theory of mind, distributed activation in the brain

\section{Introduction}

The availability of new brain imaging technologies has placed within the reach of experimental research questions about the self that seemed to be the province of philosophy a mere three decades ago. It is not surprising, then, that the attempt to understand how the self is instantiated in the brain was initially viewed with optimism [1-3]. This neuroscience of the self, however, has recently met with skepticism by several observers. Contradictory results and paradoxes have led some to argue that the field is in disarray [4], while others have gone as far as to conclude that understanding the self may be beyond the grasp of neuroscience [5].

The problem of elucidating the neural instantiation of the self stems in part from the fact that the results of brain imaging studies of self-knowledge vary according to the behavioral tasks chosen to determine the neural structures of the self [6]. While some studies have subjects perform tasks related to self-attribution of personality traits using positron emission tomography (PET) $[\mathbf{7 , 8}]$ or functional magnetic resonance imaging (fMRI) $[\mathbf{9}, \mathbf{1 0}]$, others have emphasized, instead, tasks involving self-recognition, such as distinguishing between photographs of self and photographs of others [11-14]. In the study of Lou et al., [7] for example, regional cerebral blood flow ( $\mathrm{rCBF}$ ) changes as determined by PET were examined during a retrieval memory task concerning prior judgments about personality traits of Self, a close other (Best Friend), and a far other (the Danish Queen, since the subjects were Danish). Study results found strong activation of medial prefrontral and medial parietal/posterior cingulate regions in the performance of all tasks, consistent with previous studies. Results also found that recalling self-relevant judgments differentially activated the right parietal region of the cerebral cortex, whereas judgments for close other and far other tended to activate instead the left lateral temporal region.

Results of self-attribution studies find neural activation of the medial prefrontal cortex (MPFC) as evidence of the self; studies on self-recognition tasks find correlated activation of the right prefrontal lobe and regions of the medial and left hemisphere as evidence of self-awareness and self-knowledge. Gillian and Farah [4] conclude in their meta-analysis of brain-imaging and neuropsychological studies of self-knowledge that the claims for the special status of self-related processing are not supported 
Munevar et al. Neuroscience Discovery 2014,

by the evidence and that, despite subjective experiences of a unified self, there does not seem to be a unitary, common neural system concerning the self:

Had the points clustered in certain regions or along certain networks, the hypothesis of a unitary self system would have been supported. However, neither the imaging nor the patient data implicate common brain areas across different aspects of the self. This is not surprising because there is generally little clustering even within specific aspects of the self (p. 94).

The assumption of the unity of the self, so prevalent since Descartes, receives an intensive critique at the hands of Llinas [15] who concludes that since no structure in the brain corresponds to a Cartesian self, the self does not exist. This conclusion is due, in part to Llinas's conflation of the self and the sense of the self, in line with developmental psychology research that suggests the self emerges through the infant's distinguishing his or her own experiences from those of others [16]. Llinas reasons that the self is just an internal perception; but a perception, he points out, is an illusion (other researchers would say "construction") created by the brain, therefore, the "self" is an illusion. Moreover, other theorists who conflate self and sense of self often claim that episodic memories help create our sense of self, since they are memories of the very actions that have sculpted our personality $[17,18]$. But Stanley Klein [5] has demonstrated that patients who cannot form episodic memories because they have lost their hippocampi still have a good sense of their personality, even when the personality changes.

Nevertheless, it seems to us that the results of competent experimental research may have appeared contradictory and paradoxical only because the field has inherited from Cartesian philosophy an untenable non-biological conception of the self. Thinking about the brain in the context of evolutionary biology, by contrast, leads to an alternative conception that explains the contradictions and dissolves the paradoxes while suggesting new avenues of research [19]. All organisms need to tell self from other, and in highly complex animals, that distinguishing function is performed mostly by the immune system and by the brain. As a structure that has evolved for the coordination of external information with information about the internal states of the organism, the brain takes into account previous experience of the organism and its genetic inheritance (e.g., through basic emotions that will guide survival, reproduction, etc.). The very functions that distinguish an organism from all others, and that allow it to act as a whole with respect to the social and physical environments, are the very functions normally ascribed to a self.

Since the brain/self has thus evolved for action, that is, for interaction with the social and physical environments, and such interaction may be very complex, we should expect the brain to perform a great variety of tasks as it distinguishes self from other. For this reason, and given that the brain is characteristically distributive so as to accomplish complex tasks, the self should also be expected to be distributive. Thus, an evolutionary conception of the self immediately avoids all the difficulties about central and monitoring structures that besieged traditional conceptions. Likewise, a brain-based conception of the self will recognize that most of our mental life, including self-tasks, is unconscious. Even in as simple a matter as moving, as Francis Crick [20], pointed out, we may be aware only of the "decision" taken by the brain, "but not of the computations [or reasons] that went into the decision" (p. 266). Thus the biological conception avoids the conflation of self with the sense of self, and all the problems that arise from an undue emphasis on consciousness.

In the present work we report on a self-attribution study using a blocked-design fMRI paradigm in which personality and non-personality trait adjectives were rated as to whether they applied to self or other. The study had four aims to address an evolutionary explanation concerning neural substrates of the self. First, we examined if there is distributed activation in the brain during the self-attribution task. Second, we examined whether there is activation in areas of the brain that respond to a distinction between allocentric and egocentric orientation (i.e., the ability to distinguish between self and close others in a manner that can be viewed as objective vs subjective). Third, we took into account that non-personality traits are important to the evolutionary needs of the organism by combining personality and non-personality traits in the analysis. Another aim was to test a prediction of the evolutionary model to the effect that, since humans are social animals, we should strongly identify with those close to us, although not as strongly as with ourselves. To meet the study aims, we tested four hypotheses.We hypothesized that in conditions in which personality and non-personalitytraits are combined (1) Self conditions would show a different pattern of brain activation from those shown by Best Friend (i.e., close other) and Bill Gates (i.e., far other) conditions; (2) our data should exhibit a fair degree of distributive performance by the brain in responding to these attribution tasks; and (3) the resulting patterns of activation should show some overlap with structures normally involved in preparedness to action (motion). In addition, (4) the Best Friend condition would also differ from the Bill Gates condition.

\section{Methods \\ Participants}

Participants were recruited from the Lawrence Technological University community and surrounding Detroit metropolitan area and were paid 30 dollars for their participation. The study included 13 healthy participants who reported no history of psychiatric or neurological conditions ( 6 females; range $=18-57$ years; mean age $=26.8+/-13.4$ standard deviation years). All participants were right-handed native English speakers with normal or corrected-to-normal vision. Research was approved by the Wayne State University and Lawrence Technological 
University Ethics Committees; participants gave written informed consent.

\section{Task design}

The study design was a $2 \times 3$ within-subjects factorial blocked design where participants were asked to make reflective judgments on either "Personality" (P) or "Non-personality" (N) traits about three target individuals: the "Self" (S) or a familiar close other "Best Friend" (F) or a familiar non-close other "Bill Gates" (G). For PS, PF, and PG task blocks, participants judged on a YES/NO scale if the personality trait applied to themselves (e.g., "Does the following trait apply to you?"), their best friend (e.g., "Does the following trait apply to your best friend?"), or Bill Gates (e.g., "Does the following trait apply to Bill Gates?"), respectively. On NS, NF, and NG task blocks, the same YES/NO judgments were made whether the nonpersonality trait applied to themselves, their best friend, or Bill Gates, respectively.

All participants completed the functional runscorresponding to the six conditions of the experiment: PS, PF, PG, NS, NF, and NG. Runs were conducted in the same order across participants, with approximately $60 \mathrm{sec}$ delay between conditions. Prior to the beginning of each run, participants were shown the following visual stimulus presented as a white font on a black background: "Please press YES or NO immediately after each trait word. "Within each run, there were 6 task blocks (active) and 6 rest blocks (control). Each block was comprised of 15 trials, resulting in $15 \times 6 \times 2=180$ trials per run. Task (active) trials were comprised of a trait word (e.g., "kind" for personality trait conditions, or "tall" for non-personality trait conditions) presented as a visual stimulus for $500 \mathrm{~ms}$, followed by a blank screen for $1500 \mathrm{~ms}$. Participants were instructed to press either YES (the left push-button thumb response) or NO (the right push-button response) using the presentation of the word as a prompt. Each of the 90 personality traits and 90 non-personality traits were presented at the 2000 ms inter-trial-interval regardless of the participant response during the prompt. Rest (control) trials were comprised of the letters "ABCD" presented for $500 \mathrm{~ms}$, followed by a blank screen for 1500 ms; participants were instructed to press either push-button immediately following the letters. Stimulus presentation was implemented with an Avotec MRI projector system; participants viewed the stimuli through an angled mirror attached to the head coil.

Note. In the initial testing of our paradigm we followed the presentation of each trait word with a prompt ("+"), but we found that participants tended to press the button twice: at the presentation of the word and at the presentation of the prompt, even after repeated instructions. Thus we decided to drop the redundant and potentially confounding prompt.

\section{fMRI acquisition}

Imaging was performed using a 3-Tesla Siemens Verio fMRI scanner at the MR Research Lab at Wayne State University,
Detroit, Michigan. Functional images were acquired using a gradient echo echo-planar, $\mathrm{T} 2{ }^{*}$-weighted image (repetition time $=2 \mathrm{~s}$, echo time $=30 \mathrm{~ms}$, flip angle $=90^{\circ}$, matrix $=64 \times 64$, field of view $=256 \mathrm{~mm}$ ). Thirty slices covering the brain were acquired with $4 \times 4 \times 4 \mathrm{~mm}$ voxels. The first two task and rest blocks of each run were discarded to allow for T2 stabilization effects. In addition, high-resolution anatomical T1-weighted volume scans (magnetization-prepared rapid gradient echo, MP-RAGE) were obtained for each participant for registration purposes.

\section{fMRI preprocessing}

Participant data were preprocessed using Statistical Parametric Mapping software (SPM8; http://www.fil.ion.ucl.ac.uk/spm/ software/spm8/). Preprocessing included image realignment, coregistration, normalization, and smoothing of functional and anatomical images. To eliminate motion artifacts and induced displacement, we realigned the functional images to the first image, and co-registered the functional images to the MP-RAGE from each participant. Next, functional images were normalized to the Montreal Neurological Institute (MNI) template, using the participant-specific transformation parameters created by fitting the mean functional images to the single reference Echo Planar Imaging (EPI) standard SPM template. Normalization allowed for the data from all participants to be analyzed as group data for placement in the same anatomical space. Finally, images were smoothed with an 8-mm Gaussian kernel to decrease spatial noise.

\section{Random effects analysis}

Group-wise statistical parametric maps from which inferences of the anatomical areas that distinguish self vs. others were drawn on the basis of the general linear model as implemented in SPM8. Accordingly, linear contrasts were calculated for the comparisons between conditions, and the contrasts were then entered into a second level analysis, random effects model. To account for multiple comparisons, and to account for the false positive (noise only clusters), additional analysis was performed based on extraction of $\mathrm{fMRI}$ time-series in a priori regions of interest (ROIs) using a combination of anatomical and functionally defined ROI masks. These masks were chosen using WFU_pickAtlas which is based on atlas data [21]. Following this, the segmented priori regions were evaluated for blur using the FWHM module available as part of AFNI (http://afni.nimh.nih.gov/afni/). Based on this,significant activation clusters within pre-defined ROI masks were identified using minimum cluster-size of 30 and thresholding of $p<0.001$ with correction for multiple comparisons (see critical cluster size in Tables 1-3) $[22,23]$. To produce coordinates for reference to the Talairach and Tournoux [24] brain atlas, MNI coordinates reported by SPM were transformed using the icmb_spm2tal coordinate transformation [25] supplied with the JAVA program gingerALE (http://www.brainmap.org/index.html). Next, the transformed coordinates were processed by the Talairach 
Munevar et al. Neuroscience Discovery 2014,

http://www.hoajonline.com/journals/pdf/2052-6946-2-3.pdf

doi: 10.7243/2052-6946-2-3

Table 1. Activations Self vs. Best Friend.

\begin{tabular}{lllllll}
\hline Anatomical ROI & Side & BA & $\begin{array}{l}\text { Critical cluster } \\
\text { extent }\end{array}$ & $\begin{array}{l}\text { Individual } \\
\text { cluster extent }\end{array}$ & $\begin{array}{l}\text { Corrected p-value } \\
\text { (Z-value) }\end{array}$ & $\begin{array}{l}\text { Talairach coordinates, } \\
\mathbf{x}, \mathbf{y}, \mathbf{z}\end{array}$ \\
\hline Posterior Cingulate Cortex & Right & 23 & 30 & 154 & $<.001(3.71)$ & $4,-46,24$ \\
Dorsal Posterior Cingulate & Left & 31 & 34 & 315 & $<.001(3.57)$ & $0,-46,26$ \\
\hline
\end{tabular}

Table 2. Activations Self vs. Bill Gates.

\begin{tabular}{lllllll}
\hline Anatomical ROI & Side & $\mathbf{B A}$ & $\begin{array}{l}\text { Critical cluster } \\
\text { extent }\end{array}$ & $\begin{array}{l}\text { Individual } \\
\text { cluster extent }\end{array}$ & $\begin{array}{l}\text { Corrected p-value } \\
\text { (Z-value) }\end{array}$ & $\begin{array}{l}\text { Talairach coordinates, } \\
\mathbf{x}, \mathbf{y}, \mathbf{z}\end{array}$ \\
\hline Anterior Cingulate Cortex & Left & 24 & 32 & 252 & $<.001(5.57)$ & $-2,38,0$ \\
Limbic Lobe & Left & -- & 130 & 460 & $<.001(3.54)$ & $-8,-40,-2$ \\
Caudate Nucleus & Left & -- & 30 & 120 & $<.001(2.83)$ & $-10,22,0$ \\
\hline
\end{tabular}

Table 3. Activations Best Friend vs. Bill Gates.

\begin{tabular}{lllllll}
\hline Anatomical ROI & Side & BA & $\begin{array}{l}\text { Critical cluster } \\
\text { extent }\end{array}$ & $\begin{array}{l}\text { Individual } \\
\text { cluster extent }\end{array}$ & $\begin{array}{l}\text { Corrected p-value } \\
\text { (Z-value) }\end{array}$ & $\begin{array}{l}\text { Talairach coordinates, } \\
\mathbf{x}, \mathbf{y}, \mathbf{z}\end{array}$ \\
\hline Anterior Cingulate Cortex & Left & 24 & 32 & 206 & $<.001(4.31)$ & $-4,38,0$ \\
Anterior Prefrontal Cortex & Left & 10 & 34 & 522 & $<.001(4.22)$ & $-10,54,0$ \\
Dorsal Anterior Cingulate & Right & 32 & 36 & 495 & $<.001(4.02)$ & $2,38,-2$ \\
Caudate Nucleus & Right & -- & 46 & 334 & $<.001(3.68)$ & $12,10,8$ \\
\hline
\end{tabular}

Daemon Java program (http://www.talairach.org/daemon.html) to identify corresponding brain regions.

\section{Results}

In contrasting the combined Self and Best Friend conditions we found several results of interest (Table 1). In support of Hypothesis (1) we found very significant differential activation in BA 31 (Figure 1, covering part of the posterior cingulate gyrus and the medial parietal) and the substantia nigra, and significant activation in a large variety of regions, including BA 23, right and left, the caudate tail, as well as, to a lesser extent, BA 10, which is in the frontal lobe, and the thalamus. While these results overlap with those of several previous studies on self-attribution (e.g., [7-14]), it is worth remarking that in support of Hypothesis (2), in this particular contrast (Table 1) as in all the others in our study, our results indicate that indeed a rather large number of structures distributed throughout many areas of the brain participate in what might have seem to be the rather narrow task of self-attribution. Seemingly in support of Hypothesis (3) is the very large activation of the substantia nigra, which is a key structure in the basal ganglia that serves to fine-tune successful action (in Parkinson's, the failure of the substantia nigra to produce dopamine is a crucial factor in the subsequent failure of motion). The caudate nucleus of the basal ganglia is also activated. It is important to point out that BA 31 has been identified as important for the distinction between egocentric and allocentric orientiation, that is, we may consider it as a
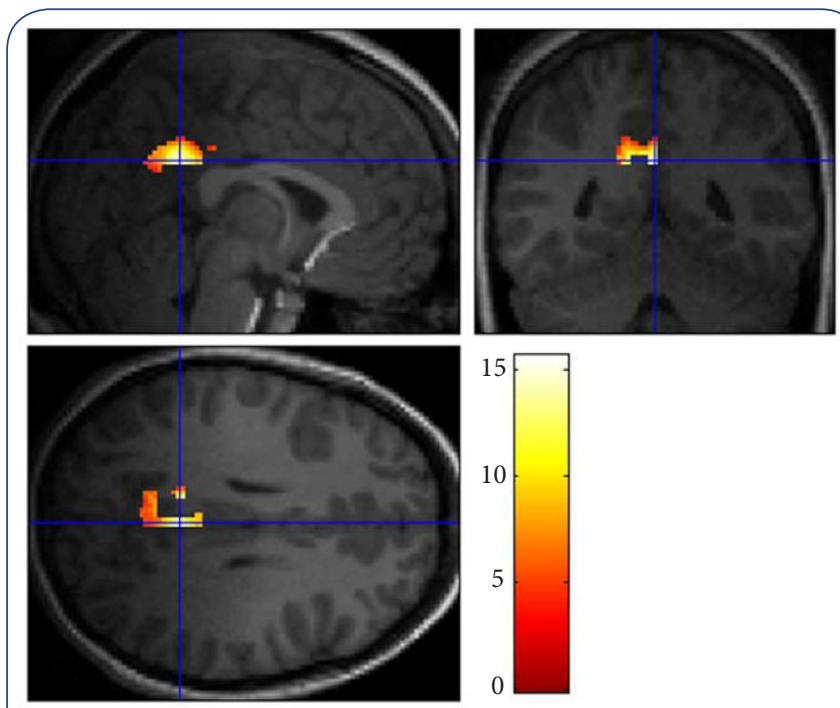

Figure 1. Activations in dorsal posterior cingulate (BA 31) in the Self vs. Best Friend conditions. Height threshold corrected p-value (Z-value) $p<0.001$ (3.57), Critical cluster extent 34 voxels. Composite picture.

region where the brain objectifies its physical relationship to the world (e.g., by using landmarks). One interesting aspect about this finding is that BA 31 is a key region for the brain to make the distinction between itself and close others.

There are interesting overlaps and differences between the contrasts Self-Bill Gates and Best Friend-Bill Gates (Tables 1 and 2). 
In the former, the greatest differential activation is in BA 24, particularly the anterior cingulate cortex (Figure 2), which supports Hypothesis (1). BA 24 was also the area where the greatest differential activation during the Best Friend-Bill Gates condition (see Figure 3), although the activation in BA 24 was not as strong as in the Self-Bill Gates condition. These results support Hypothesis (4) as well.

\section{Discussion}

Our main aim in this study was to demonstrate the experimental
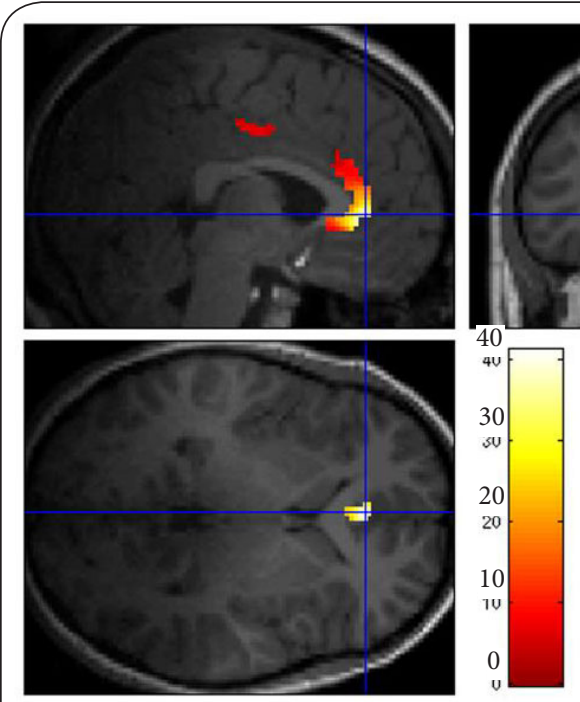

Figure 2. Activations in anterior cingulate (BA 24) in the Self vs. Bill Gates conditions. Height threshold corrected p-value (Z-value) $p<0.001$ (5.57), Critical cluster extent 32 voxels. Composite picture.

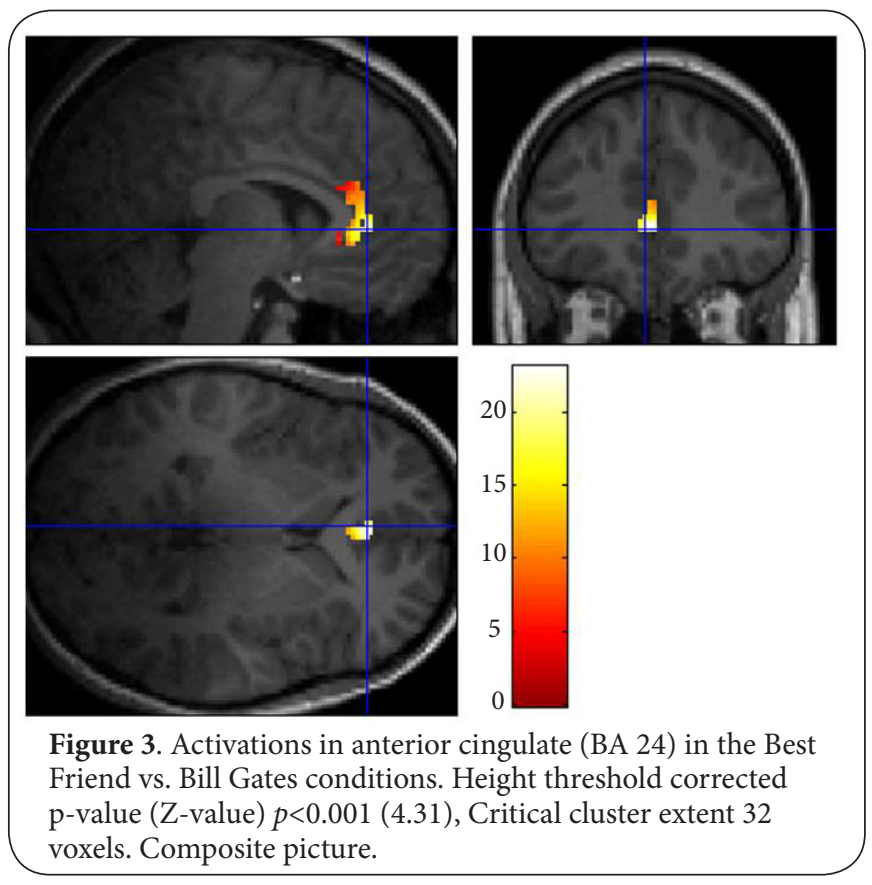

feasibility of a conception of the self as a distributive system consistent with predictions derived from evolutionary biology and neuroscience. A secondary aim was to employ the evolutionary approach to understanding the self as the platform to explain what otherwise may seem like contradictory, puzzling, or even paradoxical experimental results in the neuroscience of the self, given the traditional conception derived from Cartesian philosophy. Our results are very much in accordance with these aims. Specifically, we found an overlap of activation in the ACC (BA 24) between the self and close other conditions when compared to the far other condition (i.e., Self vs. Bill Gates and Best Friend vs. Bill Gates). We also found a distinction between self and close other was made in BA 31, the substantia nigra, and caudate nucleus. The positive result allows us to resolve the puzzle of an apparent overlap in brain stimulation in the MPFC between self-attribution and theory-of-mind tasks [36]. In the traditional conception, tasks concerning the self should instead differentiate the individual from others, including best friends, and thus should yield dissociation. In the evolutionary view, some of the same brain areas that we use for thinking about ourselves may also be used for thinking about those whose welfare is closely bound to ours.

Our results show that even the task of self-attribution involves specific brain areas acting in concert to distinguish Self from Best Friend (e.g., left BA 31 and right BA 23, see Table 1) and Self from Bill Gates (e.g., left BA 24, left limbic lobe, and left caudate nucleus, see Table 2). Different aspects of self-attribution activate different combinations of areas, some of which also seem coordinated with the brain's ability to distinguish Best Friend from Bill Gates. These results concerning the distributive nature of the self in accordance with an evolutionary approach to the self are also consistent with the findings of many other studies that complement ours in expanding the list of areas that participate in self-tasks. For example, the right frontoparietal network is involved with recognition of self-photographs [26]; the extrastriate body area (EBA) detects self-generated motion even in the absence of visual clues [27]; and the superior temporal sulcus (STS) may be involved in the representation of observed intentional actions [28]. Also, the EBA works in cooperation with the STS, ventral premotor cortex, and the angular gyrus in the posterior parietal cortex [29]. See Desmurget et al., [30] for the role of the parietal cortex in movement intentions.

An alternative conception of the self that may be thought to preserve at least a key component of the traditional conception was offered by Crick and Koch [31]. They argued that even when we do not seem to be aware of ourselves, as when we immerse in certain intense experiences, such as listening to music we love, the monitoring functions by the frontal lobe would still be carried out unconsciously - the frontal lobe would still perform a centralizing (self) function that would inform the rest of the brain that certain experiences are its own. Goldberg et al., [32], however, showed in an fMRI study that very demanding perceptual tasks actually inhibit the 
Munevar et al. Neuroscience Discovery 2014,

activation of the frontal areas that should be expected as part of the self-monitoring functions hypothesized by Crick and Koch.

Two of our results support the evolutionary expectation of a connection between the self and preparedness for action. The first is the activation of key areas of the basal ganglia such as the caudate nucleus; the second is the differential activation of BA 31 by the combined Self-conditions in contrast with the combined Best Friend-conditions, which dovetails with studies concerning allocentric orientation [33], as elucidated by Baumann and Mattingley [34].

Our results in the Best Friend vs. Bill Gates contrast are also consistent with evolutionary expectations that, being social animals, we should identify with those who are close to us, although not to the same extent as we identify with ourselves. Absent an evolutionary framework, however, observers find it puzzling that self-perception and the perception of others activate the same brain areas [35]. Mitchell et al., [36] found similar activation patterns in the MPFC, but favor an explanation along the lines of Theory of Mind $[37,38]$. Nevertheless, the puzzle remains as to why brain areas devoted to Theory of Mind should overlap with those used for selfattribution. In a closer vein to ours, Ochsner et al., [39] found a convergence of activation in the MPFC for the perception of a romantic partner.

Furthermore, areas that distinguish both Self and Best Friend from unfamiliar others are anatomically diminished in schizophrenics [40], who are presumably deficient at distinguishing self from other, with serious repercussions to their ability to function in the world. Our results seem quite consistent with expectations derived from a natural selection approach to the self.

\section{Directions for future research}

There are several directions for future research suggested by this study. First, to address a potential study limitation in which the participant's gender may have impacted both the Self vs. Best Friend comparison, and the comparison of Self and Best Friend vs. the Bill Gates condition, future research should stratify fMRI results by gender. Second, a promising direction for future research would be new avenues of research on the self by implicating self-attribution areas of the brain in which deficits in activation of the anterior cingulate may bring about deficits in being able to tell self from non-self, for example, in mental disorders such as schizophrenia. A paradigm similar to ours might also be fruitful in a study of autistics, since they also seem to differ from normals in the ways in which the brain distinguishes self from others. An additional study of advanced Alzheimer's patients, whose self might also be compromised, would make better use of a selfrecognition paradigm, particularly a self-photo recognition, since such patients would be expected to have great difficulty with language tasks.

\section{Competing interests}

The authors declare that they have no competing interests.

Authors' contributions

\begin{tabular}{|l|c|c|c|c|c|c|c|}
\hline Authors' contributions & GM & MLC & YY & JY & YZ & UK & MH \\
\hline Research concept and design & $\checkmark$ & $\checkmark$ & -- & -- & -- & -- & $\checkmark$ \\
\hline Collection and/or assembly of data & $\checkmark$ & $\checkmark$ & $\checkmark$ & -- & -- & -- & $\checkmark$ \\
\hline Data analysis and interpretation & $\checkmark$ & $\checkmark$ & $\checkmark$ & $\checkmark$ & -- & -- & $\checkmark$ \\
\hline Writing the article & $\checkmark$ & $\checkmark$ & -- & -- & $\checkmark$ & $\checkmark$ & -- \\
\hline Critical revision of the article & $\checkmark$ & $\checkmark$ & -- & -- & -- & -- & -- \\
\hline Final approval of article & $\checkmark$ & $\checkmark$ & -- & -- & -- & -- & -- \\
\hline Statistical analysis & -- & $\checkmark$ & $\checkmark$ & $\checkmark$ & -- & -- & -- \\
\hline
\end{tabular}

Acknowledgement

This work was supported by LTU Faculty Seed grants to M.L.C and G.M. Portions of these data were presented at the Nineteenth Annual Cognitive Neuroscience Society Meeting in Chicago, 2012. We also wish to thank Shunshan Li for his help with fMRI acquisition. We are thankful for the editorial support from BR.

Publication history

Editor: Bruce Rothschild, Northeast Ohio Medical University, USA. Received: 13-Jan-2014 Final Revised: 02-May-2014

Accepted: 14-May-2014 Published: 28-May-2014

\section{References}

1. Farrer $C$ and Frith $C D$. Experiencing oneself vs another person as being the cause of an action: the neural correlates of the experience of agency. Neuroimage. 2002; 15:596-603. I Article I PubMed

2. Johnson SC, Baxter LC, Wilder LS, Pipe JG, Heiserman JE and Prigatano GP. Neural correlates of self-reflection. Brain. 2002; 125:1808-14.| Article I PubMed

3. Gusnard DA, Raichle ME and Raichle ME. Searching for a baseline: functional imaging and the resting human brain. Nat Rev Neurosci. 2001; 2:685-94. | PubMed

4. Gillihan SJ and Farah MJ. Is self special? A critical review of evidence from experimental psychology and cognitive neuroscience. Psychol Bull. 2005; 131:76-97. | Article | PubMed

5. Klein S. The Cognitive Neuroscience of Knowing One's Self. In Gazzaniga MS (Ed.), The Cognitive Neurosciences III. 2004; 1077-89. Cambridge, MA: MIT Press. I Book

6. Morin A. Self-awareness and the left hemisphere: the dark side of selectively reviewing the literature. Cortex. 2007; 43:1068-73. | Article I PubMed

7. Lou HC, Luber B, Crupain M, Keenan JP, Nowak M, Kjaer TW, Sackeim HA and Lisanby SH. Parietal cortex and representation of the mental self. Proc Natl Acad Sci. 2004; 101:6827-32. | Article I PubMed Abstract | PubMed Full Text

8. Craik FIM, Moroz TM, Moscovitch M, Stuss DT, Winocur G, Tulving E and Kapur S. In search of the self: a positron emission tomography study. Psychol Sci. 1999; 1:26-34. I Article

9. Heatherton TF, Wyland CL, Macrae CN, Demos KE, Denny BT and Kelley WM. Medial prefrontal activity differentiates self from close others. Soc Cogn Affect Neurosci. 2006; 1:18-25. I Article I PubMed Abstract | PubMed Full Text

10. Moran JM, Macrae CN, Heatherton TF, Wyland CL and Kelley WM. Neuroanatomical evidence for distinct cognitive and affective components of self. J Cogn Neurosci. 2006; 18:1586-94. | Article | PubMed

11. Platek SM, Loughead JW, Gur RC, Busch S, Ruparel K, Phend N, Panyavin IS and Langleben DD. Neural substrates for functionally discriminating self-face from personally familiar faces. Hum Brain Mapp. 2006; 27:91-8. 


\section{| Article | PubMed}

12. Platek SM, Wathne K, Tierney NG and Thomson JW. Neural correlates of self-face recognition: an effect-location meta-analysis. Brain Res. 2008; 1232:173-84. | Article | PubMed

13. Keenan JP, Wheeler MA, Gallup GG Jr and Pascual-Leone A. Selfrecognition and the right prefrontal cortex. Trends Cogn Sci. 2000; 4:338-44. | Article | PubMed

14. Keenan JP, Rubio J, Racioppi C, Johnson A and Barnacz A. The right hemisphere and the dark side of consciousness. Cortex. 2005; 41:695704. | Article | PubMed

15. Llinás RR. I of the vortex: From neurons to self. 2001; Cambridge, MA: The MIT Press. | Book

16. Rochat $P$ and Hespos $S J$. Differential rooting response by neonates: Evidence for an early sense of self. Early Dev Parent. 1997; 6:105-12. | Article

17. Locksley A and Lenauer M. Considerations for a Theory of Self-Inference Processes In Cantor $\mathrm{N}$ and Kihlstrom JF (Eds.), Personality, Cognition, and Social Interaction. 1981; 263-77. Hillsdale, NJ: L. Erlbaum Associates. I Book

18. Bower GH and Gilligan SG. Remembering information related to one's self. J Res Pers. 1979; 13:420-32. | Article

19. Munevar G. A Darwinian account of self and free will. In Brinkworth $M$ and Weinert $F$ (Ed.), Evolution 2.0: Implications of Darwinism in Philosophy and the Social and Natural Sciences. 2012;43-63. New York, NY: Springer-Verlag Publishing. | Book

20. Crick F. The Astonishing Hypothesis: The Scientific Search for the Soul. 1994; New York: Scribner's Sons. I Book

21. Maldjian JA, Laurienti PJ, Kraft RA and Burdette JH. An automated method for neuroanatomic and cytoarchitectonic atlas-based interrogation of fMRI data sets. Neuroimage. 2003; 19:1233-9. | Article | PubMed

22. Cox RW and Hyde JS. Software tools for analysis and visualization of fMRI data. NIMR Biomed. 1997; 10:171-8. | Article | PubMed

23. Cox RW. AFNI: software for analysis and visualization of functional magnetic resonance neuroimages. Comput Biomed Res. 1996; 29:16273. | Article | PubMed

24. Talairach J and Tournoux P. Co-Planar Stereotaxic Atlas of the Human Brain. 1988; New York, NY: Thieme. I Book

25. Lancaster JL, Tordesillas-Gutierrez D, Martinez M, Salinas F, Evans A, Zilles $\mathrm{K}$, Mazziotta JC and Fox PT. Bias between MNI and talairach coordinates analyzed using the ICBM-152 brain template. Hum Brain Mapp. 2007; 28:1194-205. | Article | PubMed

26. Uddin LQ, Kaplan JT, Molnar-Szakacs I, Zaidel E and lacoboni M. Self-face recognition activates a frontoparietal "mirror" network in the right hemisphere: an event-related fMRI study. Neuroimage. 2005; 25:92635. | Article | PubMed

27. David N, Cohen MX, Newen A, Bewernick BH, Shah NJ, Fink GR and Vogeley $\mathrm{K}$. The extrastriate cortex distinguishes between the consequences of one's own and others' behavior. Neuroimage. 2007; 36:1004-14. | Article | PubMed

28. Saxe R and Kanwisher N. People thinking about thinking people. the role of the temporo-parietal junction in "theory of mind". Neuroimage. 2003; 19:1835-42. | Article | PubMed

29. Jacob P and Jeannerod M. Ways of seeing: The scope and limits of visual cognition. 2003; New York: Oxford University Press. I Book

30. Desmurget M, Reilly KT, Richard N, Szathmari A, Mottolese C and Sirigu A. Movement intention after parietal cortex stimulation in humans. Science. 2009; 324:811-3. | Article | PubMed

31. Crick F and Koch C. A framework for consciousness. Nat Neurosci. 2003; 6:119-26. | Article | PubMed

32. Goldberg II, Harel M and Malach R. When the brain loses its self: prefrontal inactivation during sensorimotor processing. Neuron. 2006; 50:329-39. I Article I PubMed

33. Northoff $\mathrm{G}$ and Bermpohl F. Cortical midline structures and the self.
Trends Cogn Sci. 2004; 8:102-7. I Article I PubMed

34. Baumann $\mathrm{O}$ and Mattingley JB. Medial parietal cortex encodes perceived heading direction in humans. J Neurosci. 2010; 30:12897-901. | Article I PubMed

35. Gazzaniga MS, Ivry RB and Mangun GR. Cognitive Neuroscience: The Biology of the Mind. 4th ed. 2013; New York, NY: W. W. Norton. I Book

36. Mitchell JP, Macrae CN and Banaji MR. Dissociable medial prefrontal contributions to judgments of similar and dissimilar others. Neuron. 2006; 50:655-63. I Article I PubMed

37. Kelley WM, Macrae CN, Wyland CL, Caglar S, Inati S and Heatherton TF. Finding the self? an event-related fMRI study. J Cogn Neurosci. 2002; 14:785-94. | Article | PubMed

38. MacRae CN, Heatherton TF and Kelley WM. A Self Less Ordinary: The Medial Prefrontal Cortex and You. In Gazzaniga MS (Ed.),The Cognitive Neurosciences III. 2004; 1067-75. Cambridge, MA: MIT Press. | Book

39. Ochsner KN, Beer JS, Robertson ER, Cooper JC, Gabrieli JD, KihsItrom JF and $D^{\prime}$ Esposito $M$. The neural correlates of direct and reflected selfknowledge. Neuroimage. 2005; 28:797-814. | Article | PubMed

40. Fornito A, Yucel M, Dean B, Wood SJ and Pantelis C. Anatomical abnormalities of the anterior cingulate cortex in schizophrenia: bridging the gap between neuroimaging and neuropathology. Schizophr Bull. 2009; 35:973-93. | Article | PubMed Abstract | PubMed Full Text

41. Decety J and Grezes J. The power of simulation: Imagining one's own and other's behavior. Brain Res. 2006; 1079:4-14. | Article | PubMed

\section{Citation:}

Munevar G, Cole ML, Ye Y, Yang J, Zheng Y, Krishnamurthy $U$ and Haacke M. fMRI study of self vs. others' attributions of traits consistent with evolutionary understanding of the self. Neurosci Discov. 2014; 2:3. http://dx.doi.org/10.7243/2052-6946-2-3 